\title{
POST-OPERATIVE OUTCOME IN ELECTIVE SURGERIES
}

Sylverson P. Rassi', Ruffo Freitas-Junior ${ }^{1}$

1Premium Hospital - Goiânia (GO), Brazil.

Objectives: To describe the incidence of adverse events in the post-operative (PO) period of elective plastic surgeries. Methodology: This is a prospective, observational, and descriptive real-life study conducted in a single hospital center. A total of 499 patients were included in the sample, who submitted to plastic surgeries from June to November 2017, performed exclusively by members of the Brazilian Society of Plastic Surgery - SBCP. The adverse events description concerning to the post-operative period was made through data obtained by the phone survey on the $7^{\text {th }}$ and $30^{\text {th }} \mathrm{PO}$ days. Results: There was a low rate of identified adverse events (1.9\%), without statistically significant correlation among local and systemic symptoms reported through the phone survey in the $7^{\text {th }} \mathrm{PO}$ and $30^{\text {th }} \mathrm{PO}$ days, neither with the size of the surgeries performed ( $>0.05)$. There were no deaths and no severe adverse events in the present series. Conclusion: This study produced reliable results allowing the description of the low occurrence of adverse events and the importance of active search after hospital discharge. 